\title{
Dynamic hyperinflation and pulmonary inflammation: a potentially relevant relationship?
}

\author{
A. Agusti*,\# and J.B. Soriano ${ }^{\#}$
}

ABSTRACT: In patients with moderate-to-severe chronic obstructive pulmonary disease (COPD), end-expiratory lung volume increases under conditions of greater minute ventilation (e.g. exercise). This abnormal response is termed dynamic hyperinflation (DH) and has now been recognised as a key determinant of symptomatology and exercise intolerance in COPD. Reduced elastic recoil, loss of alveolar attachments and increased airway resistance are the mechanical factors traditionally invoked to explain the occurrence of DH in COPD. An abnormal inflammatory response to, most frequently, tobacco smoking is a key pathophysiological component of COPD, but its potential relationship with $\mathrm{DH}$ has not been directly investigated and is poorly understood. The present article discusses, first, the mechanisms by which DH can enhance inflammation in COPD (including cellular stretching, tissue damage and danger signals, hyperventilation and hypoxia). It then reviews how the abnormal inflammatory response that characterises the disease can augment DH (oedema and increased airway resistance, increased mucus production and alveolar destruction). Finally, it speculates that if these relationships eventually prove to be real, then the use of long-acting bronchodilators may help reduce the inflammatory load of these patients and, conversely, the use of anti-inflammatory therapy can contribute to the reduction of DH.

KEYWORDS: Bronchodilators, chronic bronchitis, dyspnoea, emphysema, exercise, steroids

$\mathbf{T}$ he term dynamic hyperinflation $(\mathrm{DH})$ refers to the increase in end-expiratory lung volume (EELV) that may occur in patients with airflow limitation when minute ventilation increases (e.g. during exercise, hypoxia, anxiety etc.) $[1,2]$. DH often occurs in patients with moderate-to-severe chronic obstructive pulmonary disease (COPD) and it has now been recognised as a key determinant of symptoms and exercise intolerance in these patients [3].

$\mathrm{DH}$ in COPD is traditionally explained on the basis of the abnormal lung mechanics that characterise this disease $[1,2]$. Factors such as reduced elastic recoil, loss of alveolar attachments and increased airway resistance are normally quoted to explain the occurrence of $\mathrm{DH}$ in patients with COPD [1, 2]. The role and interaction among these different mechanical factors has been reviewed elsewhere [1, 2] and will not be discussed here any further. In contrast, the potential relationships between $\mathrm{DH}$ and inflammation, a key pathophysiological component of COPD [4,5], have been much less investigated and are far less well understood. Given the key role of both $\mathrm{DH}$ and inflammation in COPD, a better understanding of these previously unexplored relationships may have potentially relevant clinical implications.

This manuscript discusses: first, the different mechanisms by which $\mathrm{DH}$ can contribute to inflammation in COPD; and secondly, how, conversely, inflammation can contribute to the pathogenesis of DH in COPD. Finally, although many of these potential relationships between $\mathrm{DH}$ and inflammation are, admittedly, speculative, their potential clinical implications are also highlighted and discussed. The final goal of the present article is to stimulate research into an area that is largely unexplored but potentially relevant to a better understanding of COPD pathophysiology and to eventually improve patient management and outcomes.

\section{PRO-INFLAMMATORY EFFECTS OF DH}

$\mathrm{DH}$ can exert pro-inflammatory effects through a number of potential mechanisms (fig. 1); perhaps the most obvious is cellular stretch. Several studies have now shown that cellular stretch is a potent pro-inflammatory stimulus. For instance, VLAHAKIS et al. [6] showed that alveolar epithelial

\section{AFFILIATIONS}

*Hospital Universitario Son Dureta, Palma de Mallorca, and \#Fundación Caubet-Cimera, IIles Balears, Spain.

CORRESPONDENCE A. Agusti

Hospital Universitari Son Dureta Andrea Doria 55

07014 Palma de Mallorca Spain

Fax: 34971175228

E-mail: aagusti@hsd.es 


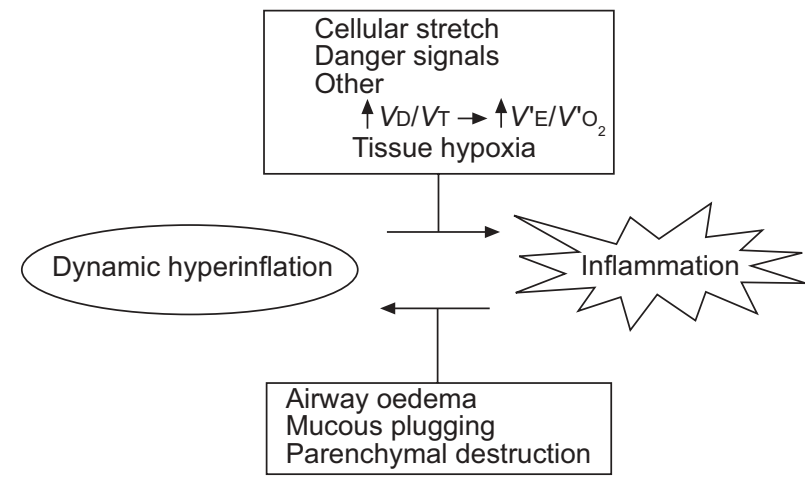

FIGURE 1. Potential mechanisms relating dynamic hyperinflation and inflammation in patients with chronic obstructive pulmonary disease. $V_{D}$ : dead space volume; $V T$ : tidal volume; $V^{\prime} E$ : minute ventilation; $V^{\prime} \mathrm{O}_{2}$ : oxygen uptake.

cells cultured on a deformable silico-elastic membrane and stretched by $30 \%$ for up to $48 \mathrm{~h}$, released $\sim 50 \%$ more interleukin (IL)-8 than static controls $(\mathrm{p}<0.001)$. Furthermore, it is well known that by overdistending alveolar regions, mechanical ventilation can induce a cytokine response characterised by increased concentrations of IL-1 $\beta$, IL- 6 and IL-1 receptor agonist, tumour necrosis factor (TNF)- $\alpha$ and TNF- $\alpha$ receptors in bronchoalveolar lavage and plasma, and that this inflammatory response may be attenuated by a strategy to minimise overdistention of the lung [7].

The so-called "danger signals" are key controllers of the inflammatory response [8]. A principal endogenous danger signal released by injured mammalian cells is uric acid [8]. Uric acid stimulates dendritic cell maturation and, when co-injected with antigen in vivo, significantly enhances the generation of responses from CD8+ T-cells [8]. Several articles have shown that mechanical forces during breathing are capable of causing failure of the remodelled extracellular matrix at loci of stress concentrations and therefore contribute to the progression of emphysema [9-12]. Thus, by causing cell stretch DH has the potential to contribute to cell injury. If so, through the release of danger signals, $\mathrm{DH}$ can also contribute to the enhancement of the inflammatory response and/or jeopardise tissue repair.

Finally, there are other potential mechanisms that, although speculative, less apparent and acting indirectly, may also contribute to the enhancement of the pro-inflammatory effects of DH. For instance, the mechanical factors that cause $\mathrm{DH}$ (reduced elastic recoil, loss of alveolar attachments and increased airway resistance) also cause ventilation/perfusion inequalities and, in patients with COPD in particular, increased wasted ventilation [13]. This implies that for any given exercise load, minute ventilation should be higher than normal in order to provide enough oxygen to sustain the metabolic demand [14]. Several studies have shown that hyperventilation can be pro-inflammatory in itself. For instance, DAVIS and FREED [15] showed that exercise-induced hyperpnoea increased the concentration of neutrophils, eosinophils and leukotrienes in the bronchoalveolar lavage fluid of experimental animals. Likewise, the structural abnormalities of the lung parenchyma that characterise COPD (bronchitis, bronchiolitis and alveolar emphysema) can jeopardise pulmonary gas exchange and cause tissue hypoxia. The links between the latter and inflammation are also well recognised [16].

\section{INFLAMMATION CAN CONTRIBUTE TO DH}

There are several mechanisms by which inflammation can contribute to the pathogenesis of $\mathrm{DH}$ and most of them are quite apparent (fig. 1). Oedema is one of the key components of inflammation. Airway oedema increases airway resistance and has, therefore, the potential to produce $\mathrm{DH}$.

Neutrophils are important effector cells in the abnormal inflammatory response that characterises COPD [17]. Neutrophil elastase is a very potent secretagogue [18] and excess mucus production is one of the cardinal clinical features of COPD [4]. Increased mucus production can lead to mucous plugging, which has the potential to limit airflow and, therefore, contribute to the pathogenesis of $\mathrm{DH}$.

Alveolar destruction (emphysema) is another key component of COPD [4]. Chronic inflammation is thought to play a key role in the pathogenesis of emphysema [4]. One of the main consequences of emphysema is loss of elastic recoil, which is also a key determinant of $\mathrm{DH}$ [2]. Thus, the relationship between chronic inflammation, emphysema and $\mathrm{DH}$ seems straightforward.

\section{POTENTIAL IMPLICATIONS}

The relationships previously outlined between $\mathrm{DH}$ and inflammation are speculative and by no means comprehensive. However, a better understanding of these relationships is of great potential clinical relevance because both $\mathrm{DH}$ and chronic inflammation are key pathogenic components of COPD and can both be potentially modified by current therapies (longacting bronchodilators and inhaled steroids). Thus, by reducing one of them, it is theoretically possible to influence the other one.

$\mathrm{DH}$ is one of the main factors limiting exercise capacity (and, consequently, health status) in these patients. Current bronchodilator therapy is effective in reducing $\mathrm{DH}$, in alleviating symptoms and in improving exercise capacity in patients with COPD [4]. Actually, bronchodilator therapy currently forms the cornerstone of the management strategy in these patients [4]. What is less often realised is that, if the links discussed previously between $\mathrm{DH}$ and inflammation are true (fig. 1), then bronchodilator therapy in COPD may not only decrease $\mathrm{DH}$ (and hence improve symptoms and exercise capacity) but may also contribute by itself to the reduction of the inflammatory load that occurs in these patients, both within and outside the lungs [4]. If this is the case, this might have an impact upon other important outcomes, such as acute exacerbations, cancer, cardiovascular disease and death [19].

Conversely, if chronic inflammation has the potential to contribute to $\mathrm{DH}$ (fig. 1), then anti-inflammatory therapy would also be expected to contribute to its reduction. Surprisingly, and to the best of the present authors' knowledge, no published study has explored this possibility directly so far. However, some indirect evidence may support it. First, a post hoc analysis of a study investigating the effects of the antioxidant molecule $\mathrm{N}$-acetylcysteine on lung function decline found that, in a subgroup of patients, the chronic use of this molecule (to some extent, an anti-inflammatory molecule) had 
an effect on hyperinflation [20]. Secondly, several studies have clearly shown positive clinical effects resulting from the combination of bronchodilator therapy and inhaled steroids upon several relevant clinical outcomes in COPD [21-23]. Finally, there are a number of population-based studies that link COPD severity to inflammatory markers, mainly in the Third National Health and Nutrition Examination Survey (NHANES-III) [24, 25]. To date, no DH population data are available, simply because EELV and other parameters were not measured. Ongoing natural history studies might collect EELV or other DH data. An epidemiological association would add weight to the potential causality of the relationship between $\mathrm{DH}$, inflammation and COPD [26].

\section{CONCLUSIONS}

The relationship between dynamic hyperinflation and inflammation in patients with chronic obstructive pulmonary disease is poorly understood but is of great potential relevance. There are a number of mechanisms via which dynamic hyperinflation can have pro-inflammatory effects and several pathways via which chronic inflammation can contribute to dynamic hyperinflation. In fact, it is possible that by treating dynamic hyperinflation with bronchodilator therapy, inflammation is actually being influenced and, vice versa, by using antiinflammatory drugs, dynamic hyperinflation and its consequences may actually be decreased, mainly the symptoms and exercise intolerance. Although these possibilities will have to be tested directly in future studies, the consideration of potential relationships between dynamic hyperinflation and inflammation may open up new avenues in the understanding and treatment of chronic obstructive pulmonary disease.

\section{REFERENCES}

1 Parker CM, O'Donnell DE. Dynamic hyperinflation, dyspnoea and exercise intolerance in chronic obstructive pulmonary disease. In: Barnes PJ, Postma DS, eds. Essentials of COPD. Alphen a/d Rijn, Van Zuiden Communications B.V., 2005; pp. 2-30.

2 Calverley PMA, Koulouris NG. Flow limitation and dynamic hyperinflation: key concepts in modern respiratory physiology. Eur Respir J 2005; 25: 186-199.

3 O'Donnell DE, D'Arsigny C, Fitzpatrick M, Webb KA. Exercise hypercapnia in advanced chronic obstructive pulmonary disease: the role of lung hyperinflation. Am J Respir Crit Care Med 2002; 166: 663-668.

4 Celli BR, MacNee W, Agusti AG, et al. Standards for the diagnosis and treatment of patients with COPD: a summary of the ATS/ERS position paper. Eur Respir J 2004; 23: 932-946.

5 Pauwels RA, Buist AS, Calverley PM, Jenkins CR, Hurd SS. Global strategy for the diagnosis, management, and prevention of chronic obstructive pulmonary disease. NHLBI/WHO Global Initiative for Chronic Obstructive Lung Disease (GOLD) Workshop summary. Am J Respir Crit Care Med 2001; 163: 1256-1276.
6 Vlahakis NE, Schroeder MA, Limper AH, Hubmayr RD. Stretch induces cytokine release by alveolar epithelial cells in vitro. Am J Physiol 1999; 277: L167-L173.

7 Ranieri VM, Suter PM, Tortorella C, et al. Effect of mechanical ventilation on inflammatory mediators in patients with acute respiratory distress syndrome: a randomized controlled trial. JAMA 1999; 282: 54-61.

8 Shi Y, Evans JE, Rock KL. Molecular identification of a danger signal that alerts the immune system to dying cells. Nature 2003; 425: 516-521.

9 Mishima M, Hirai T, Itoh $\mathrm{H}$, et al. Complexity of terminal airspace geometry assessed by lung computed tomography in normal subjects and patients with chronic obstructive pulmonary disease. Proc Natl Acad Sci USA 1999; 96: 8829-8834.

10 Kononov S, Brewer K, Sakai H, et al. Roles of mechanical forces and collagen failure in the development of elastaseinduced emphysema. Am J Respir Crit Care Med 2001; 164: 1920-1926.

11 Suki $B$, Lutchen KR, Ingenito EP. On the progressive nature of emphysema: roles of proteases, inflammation and mechanical forces. Am J Respir Crit Care Med 2003; 168: 516-521.

12 Ingenito EP, Tsai LW, Majumdar A, Suki B. On the role of surface tension in the pathophysiology of emphysema. Am J Respir Crit Care Med 2005; 171: 300-304.

13 Agustí AGN, Barberá JA. Chronic pulmonary diseases: chronic obstructive pulmonary disease and idiopathic pulmonary fibrosis. Thorax 1994; 49: 924-932.

14 Agustí AGN, Cotes J, Wagner PD. Responses to exercise in lung diseases. Eur Respir Mon 1997; 6: 32-50.

15 Davis MS, Freed AN. Repeated hyperventilation causes peripheral airways inflammation, hyperreactivity, and impaired bronchodilation in dogs. Am J Respir Crit Care Med 2001; 164: 785-789.

16 Zünd G, Uezon S, Stahl GL, et al. Hypoxia enhances induction of endothelial ICAM-1: role for metabolic acidosis and proteasomes. Am J Physiol (Cell Physiol) 1997; 273: C1571-C1580.

17 Baraldo S, Turato G, Badin C, et al. Neutrophilic infiltration within the airway smooth muscle in patients with COPD. Thorax 2004; 59: 308-312.

18 Nadel JA. Role of neutrophil elastase in hypersecretion during COPD exacerbations, and proposed therapies. Chest 2000; 117: 386S-389S.

19 Sin DD, Man SF. Why are patients with chronic obstructive pulmonary disease at increased risk of cardiovascular diseases? The potential role of systemic inflammation in chronic obstructive pulmonary disease. Circulation 2003; 107: 1514-1519.

20 Decramer M, Rutten-Van Molken M, Dekhuijzen PN, et al. Effects of $\mathrm{N}$-acetylcysteine on outcomes in chronic obstructive pulmonary disease (Bronchitis Randomized on NAC Cost-Utility Study, BRONCUS): a randomised placebo-controlled trial. Lancet 2005; 365: 1552-1560.

21 Calverley P, Pauwels R, Vestbo J, et al. Combined salmeterol and fluticasone in the treatment of chronic obstructive pulmonary disease: a randomised controlled trial. Lancet 2003; 361: 449-456.

22 Vestbo J, Pauwels R, Anderson JA, Jones P, Calverley P, on behalf of the TRISTAN study group. Early onset of effect of 
salmeterol and fluticasone propionate in chronic obstructive pulmonary disease. Thorax 2005; 60: 301-304.

23 Szafranski W, Cukier A, Ramirez A, et al. Efficacy and safety of budesonide/formoterol in the management of chronic obstructive pulmonary disease. Eur Respir J 2003; 21: 74-81.

24 Mannino DM, Ford ES, Redd SC. Obstructive and restrictive lung disease and markers of inflammation: data from the
Third National Health and Nutrition Examination. Am J Med 2003; 114: 758-762.

25 Gan WQ, Man SF, Sin DD. The interactions between cigarette smoking and reduced lung function on systemic inflammation. Chest 2005; 127: 558-564.

26 Hill AB. The environment and disease: association or causation? Proc R Soc Med 1965; 58: 295-300. 